\title{
Mucus-secreting 'signet-ring' cells in CSF revealing the site of primary cancer
}

\author{
Giancarlo Agnelli \\ M.D.
}

\author{
Paolo Gresele \\ M.D.
}

Institute of Clinical Medicine, University of Perugia, Perugia, Italy

\begin{abstract}
Summary
A case is reported of leptomeningeal carcinomatosis in which identification of mucus-secreting 'signetring' carcinoma cells in the CSF allowed diagnosis of an otherwise asymptomatic gastric cancer.

When lumbar puncture is performed, careful cytological examination of the CSF should be carried out in any undiagnosed patient with neurological symptoms and signs.
\end{abstract}

\section{Introduction}

Leptomeningeal metastases from non-leukaemic tumours occur in about $4 \%$ of patients brought to post-mortem with systemic cancer (Posner, 1977). Ante-mortem diagnosis is frequently missed (Olson, Chernik and Posner, 1974; Little, Dale and Okazaki, 1974). Examination of cerebrospinal fluid is the most helpful diagnostic procedure. Symptoms and signs arising from meningeal infiltration by metastatic cells from a primary carcinoma outside the CNS may be, although rarely, the first evidence of malignancy (Meissner, 1953; Grain and Karr, 1955; Heathfield and Williams, 1956; Dinsdale and Taghavy, 1964; Olson et al., 1974; Little et al., 1974). The authors now describe a case in which clinical symptoms and signs of meningeal involvement were the first manifestation of disease and in which the identification of mucus-producing carcinoma cells in the CSF allowed diagnosis of an otherwise asymptomatic gastric cancer.

\section{Case report}

A 49-year-old man with no previous serious illness was admitted to the Istituto di Clinica Medica, Perugia, for evaluation of severe occipital and frontal headache, nausea and vomiting of several days' duration. There were scotomas, diplopia, anaesthesiae of arms and abdomen, spells of vertigo and sweats. There was no evidence of change in mental state, fits, other cranial nerve involvement, focal weakness, or bladder and bowel dysfunction. On admission he looked fairly fit, although he had recently lost weight; BP was $130 / 100 \mathrm{mmHg}$, pulse $60 / \mathrm{min}$ and temperature $36.5^{\circ} \mathrm{C}$. Clinical examination revealed mild nuchal rigidity, bilateral pain on straight leg raising, and ataxia of gait. Deep tendon reflexes were absent, and both plantar responses remained flexor. Speech and intellectual functions were normal. Fund were normal. Diplopia was confirmed; nystagmus was absent.

No physical abnormality was found outside the nervous system; in particular, there was no glandular enlargement.

The $\mathrm{Hb}$ level was $16.8 \mathrm{~g} / \mathrm{dl}$, WBC $8.6 \times 10^{9} / \mathrm{B}$ and ESR $5 \mathrm{~mm} / \mathrm{hr}$ (Westergren). Laboratory exane ination showed normal blood chemistry value except for an increase in alkaline phosphatase Urinalysis was negative; stool showed a negative guaiacum reaction. A chest $\mathrm{X}$-ray revealed no abnormality. The ECG showed sinus bradycardia $(54 / \mathrm{min})$. Bone $\mathrm{X}$-rays excluded metastases. The EEG was generally slow with intermittent bitemporal theta activity and without focal features. Skull films showed decalcification of posterior clinoid processes and dorsum sellae, findings suggestive of increased intracranial pressure. Brain scan was negative. Left carotid angiography was helpful in ruling out a parenchymal mass lesion and hydrocephalus. A lumbar puncture was performed: the open pressure was $800 \mathrm{mmH}_{2} \mathrm{O}$, protein content was $1.5 \mathrm{~g} / 1$; glucose content, $0.44 \mathrm{~g} / 1$; leucocytes $0.060 \times 10^{9} / 1$, predominantly lymphocytes. Bacteriological examination of CSF by routine smear and culture was negative. No organisms were seen on a Ziehl-Neelsen stained film. As diagnosis remained uncertain, the patient was started on full 0 anti-tuberculous treatment.

The headache grew steadily worse, and 6 days after the first lumbar puncture, another was performed. Cytological examination of the Papanicolaou-stained CSF preparation revealed mucus-

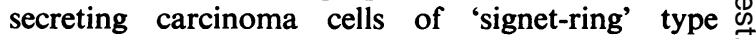
(Fig. 1).

Anti-tuberculous treatment was therefore stopped 


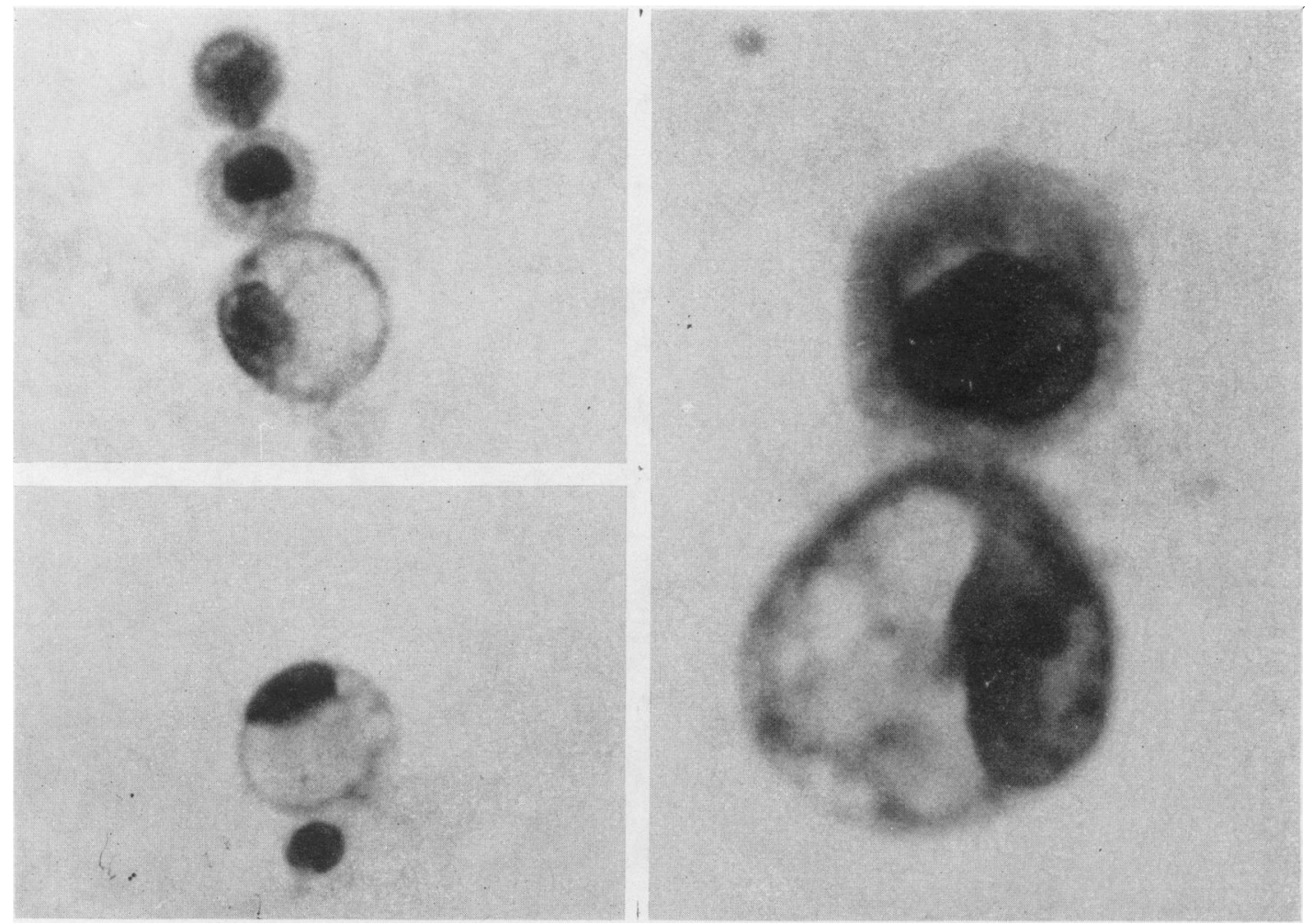

FIG. 1. Papanicolaou stain of the spinal fluid showing mucus-secreting 'signet-ring' carcinoma cells containing intracytoplasmic mucin and laterally displaced nucleus (on the left $\times 400$; and on the right $\times 1000$ ).

and methotrexate, $20 \mathrm{mg}$, was instilled intrathecally with only slight improvement of the patient's condition. Subsequent upper endoscopy showed a non-ulcerative, polypoid mass with broad attachment on the anterior wall of the body of the stomach (Borrmann's Type I). Histological examination of multiple biopsies revealed a mucus-secreting carcinoma composed of sheets of 'signet-ring' cells (Fig. 2).

Bone scan showed multiple metastases. During the next few days the headache became increasingly severe and was relieved only by lumbar puncture. The patient was discharged home 4 weeks after admission; he died at home 2 months after the onset of neurological symptoms.

\section{Discussion}

Diffuse infiltration of the leptomeninges by malignant cells metastasizing from a primary carcinoma outside the nervous system may be the first evidence of malignancy (Olson et al., 1974; Little et al., 1974). A correct diagnosis is not often appreciated at the time of the initial evaluation because leptomeningeal carcinomatosis clinically resembles a meningitis, especially a tuberculous one, rather than a tumour (Fischer-Williams, Bosanquet and Daniel, 1955; Hughes, Hume Adams and Ilbert, 1963). Indeed, careful and complete neurological examination often reveals multifocal symptoms and signs as the expression of the involvement of the cerebrum, cranial nerves and spinal root (Posner, 1971; Olson et al., 1974). Focal symptoms and signs due to meningeal carcinomatosis may be present even at an early stage in contrast to tuberculous meningitis when they usually do not appear until the late stages of disease (Olson et al., 1974).

The most important investigation in confirming the clinical diagnosis of leptomeningeal carcinomatosis is the cytological examination of the spinal fluid, even in those rare instances where other CSF findings may be normal (Reuler and Meier, 1979).

However, as pointed out by many authors, repeated spinal taps may be necessary to identify malignant cells (Olson et al., 1974; Little et al., 1974; Posner, 1977). Furthermore, cytological features of malignant cells in the CSF may help to orientate the investigation toward the site of 

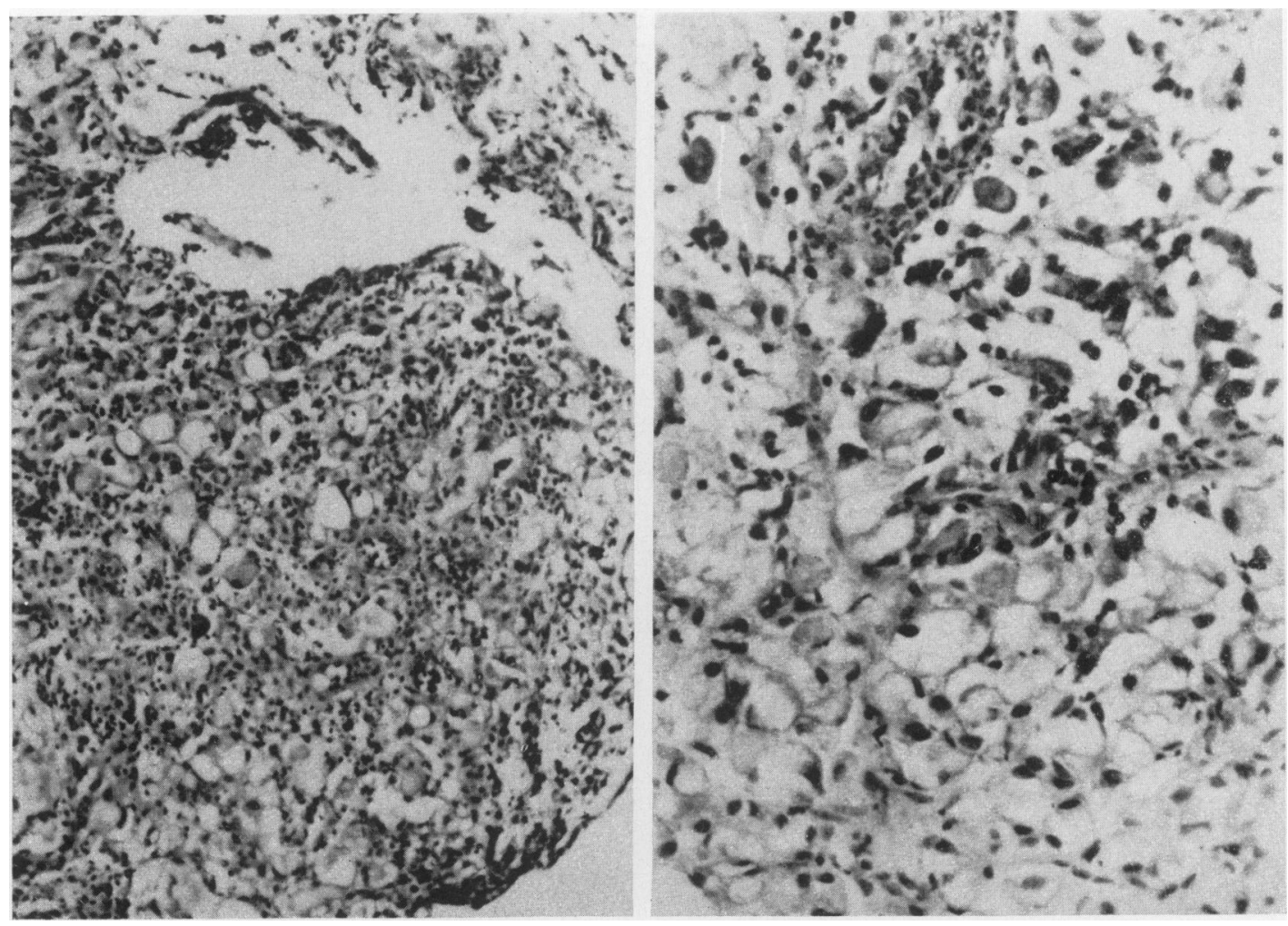

FIG. 2. Mucus-secreting carcinoma of the stomach. Sheets of 'signet-ring' carcinoma cells. Bioptic specimen (HE, on the left $\times 80$; on the right $\times 140$ ).

primary cancer (Spriggs, 1954). Other diagnostic procedures are important only in that they help to rule out the presence of other neurological lesions. In the present patient, leptomeningeal carcinomatosis was the first and only manifestation of gastric cancer and the finding of mucus-secreting carcinoma 'signet-ring' cells in the CSF proved to be determinant in directing the authors toward the digestive system.

\section{References}

Dinsdale, H.B. \& Taghavy, A. (1964) Carcinomatosis of the meninges. Canadian Medical Association Journal, 90, 505.

Fischer-Williams, M., Bosanquet, F.D. \& Daniel, P.M. (1955) Carcinomatosis of the meninges: a report of three cases. Brain, 78, 42.

Grain, G.O. \& KarR, J.P. (1955) Diffuse leptomeningeal carcinomatosis. Clinical and pathologic characteristics. Neurology, 5, 706 .

Heathfield, K.W.G. \& Williams, J.R.B. (1956) Carcino- matosis of the meninges. Some clinical and pathologica 음 aspects. British Medical Journal, 1, 328.

Hughes, I.E., Hume Adams, J. \& Ilbert, R.C. (1963) Invasion of the leptomeninges by tumour: The differential $\bar{O}$ diagnosis from tuberculous meningitis. Journal of 3 Neurology, Neurosurgery and Psychiatry, 26, 83.

LitTle, J.R., DALE, A.J.D. \& OKAZAKI, H. (1974) Meningeal carcinomatosis: Clinical manifestations. Archives of Neurology, 30, 138.

MeISSNER, G.F. (1953) Carcinoma of the stomach with meningeal carcinosis. Report of four cases. Cancer, $\overline{3}$ 6, 313 .

Olson, M.E., Chernik, N.L. \& Posner, J.B. (1974) Infiltration of the leptomeninges by systemic cancer: A clinical and pathologic study. Archives of Neurology, 30, 122.

PoSNER, J.B. (1971) Neurological complications of systemic 을 cancer. Medical Clinics of North America, 55, 625.

PoSNer, J.B. (1977) Management of central nervous system $\frac{7}{6}$ metastases. Seminars in Oncology, 4, 81.

REuler, J.B. \& MeIER, D. (1979) Leptomeningeal carcino- N matosis with normal CSF features. Archives of Internal Medicine, 139, 237.

SpRIGGS, A.I. (1954) Malignant cells in cerebro-spinal fluid. Journal of C linical Pathology, 7, 122.
N 